\title{
La Orden de San Jerónimo en España
}

La Orden de San Jerónimo celebró en 1973 el VI centenario de su fundación en España. Entre los actos programados, cobraron especial relieve cultural la exposición de motivos jeronimianos en la Biblioteca Nacional y la publicación de Stvdia Hieronymiana ${ }^{1}$, miscelánea de cuarenta y cinco colaboraciones, entre las que figuran las firmas de los agustinos Balbino Rano ${ }^{2}$ y Angel Custodio Vega ${ }^{3}$.

Seiscientos años de historia separan, pues, al reducido grupo de monjes que actualmente habitan los cuatro monasterios de la restaurada Orden jerónima ", de aquel otro, también exiguo, que la fundó en el de S. Bartolomé de Lupiana, haciendo "profesión en manos de fray Pedro Fernández de Guadalajara, de la suerte que él la había hecho en las del Papa" ", Gregorio XI, el 2 de febrero de 1374.

Fray José de Sigüenza, a cuyo conocimiento han contribuido notablemente los importantes estudios de los religiosos agustinos vinculados al monasterio de El Escorial ${ }^{6}$, escribió con lenguaje preciso y estilo perfecto la Historia de la Orden de San Jerónimo durante sus doscientos primeros años de existencia. Comienza dándonos a conocer los oscuros principios de la Orden de los jerónimos en Castilla hacia el año 1350, en los comienzos del reinado de Pedro I el Cruel ${ }^{7}$ hasta Felipe II, en que la historia se convierte para el P. Sigüenza en viva actualidad.

1. Stvdia Hieronymiana, 2 t., Madrid, Ribadeneyra, 1973.

2. El monasterio de Santa María del Santo Sepulcro en Cámpora (Florencia) y la fundación de la Orden de San Jerónimo, en Stvdia Hieronymiana, I, Madrid, 1973, págs. 75-102.

3. El retrato del Padre Sigüenza, en Stvdia Hieronymiana, I, págs. 521-530.

4. Santa María del Parral (Segovia), restaurado en 1925; San Isidoro del Campo (Sevilla), en 1956; San Jerónimo de Yuste (Cáceres), en 1958; y Santa María de los Angeles de Jávea (Alicante), en 1964.

5. José DE Sigüenza, Historia de la Orden de San Jerónimo, t. I, Madrid, Nueva Biblioteca de Autores Españoles, 8, 1907, pág. 36.

6. Tales como Fr. Luis Villalba Muñoz, Fr. Julián Zarco Cuevas, Fr. Guillermo Antolín, Fr. Saturnino Alvarez Turienzo, etc.

7. José DE SIGǗnza, ob. cit., pág. 9-10. 
¿En qué marco histórico y espiritual nació la Orden de San Jerónimo en España y cómo se consolidó su fundación y extensión? ¿Qué significación ha tenido en la espiritualidad española y cuáles han sido sus principales incidencias hasta nuestros días?

\section{Precedentes espirituales}

La pujanza de la vida monástica carolingia comenzó a decaer cuando se vio sometida a la gran tensión del feudalismo y las encomiendas laicas durante los siglos VIII y IX. Junto a la prosperidad económica de las abadías benedictinas brotó la relajación espiritua! entre los monjes. San Benito de Aniano realizó el más vigoroso esfuerzo de su época para restablecer en los monasterios la austeridad y sencillez primitivas de la Regla benedictina en los últimos años del siglo VIII y durante el primer tercio del siglo IX; pero la decadencia invadía a la Iglesia occidental y terminó por sofocar la reforma anianense.

En medio de aquel "saeculum ferreum obscurum", que atormentó a la Iglesia envolviéndola en luchas enconadas por el dominio y el poder, y desgarrándola en desórdenes y cismas, surgieron las grandes fundaciones monásticas del siglo $X$. Cluny es el renacimiento monástico que pronto esparciria su influencia por toda la cristiandad occidental. Pero no puede olvidarse ni menospreciar el florecimiento del monacato en la España reconquistada de los reinos de Asturias, León, Castilla, Aragón y Cataluña. No obstante, la reforma clunyacense se abrió amplio camino por todo el Occidente cristiano.

En Italia, San Romualdo encarnó la austeridad del anacoreta y la reforma del espíritu religioso por medio de la vida penitente. Organizó la vida eremítica y fundó en las crestas de los Apeninos la Camáldula. A su espíritu de reforma le infundió vuelos más universales San Pedro Damiani, que reunió en su persona la rigurosidad del ascetismo de San Romualdo, la penetración del sabio y la comunicación del escritor, cualidades a las que se sumaban la visión transfigurante del santo y del poeta. Aunque Cluny representó el espíritu reformador del monacato del siglo XI, no debe soslayarse esta nueva corriente reorganizadora del eremitismo, emprendida por San Romualdo y San Pedro Damiani.

El fenómeno de la vida eremítica de los solitarios anacorètas, que viven a la sombra de las grandes abadías y monasterios, benefi- 
ciándose tanto en lo espiritual como en lo material de las comunidades a las que se acogen, supuso un signo de riqueza espiritual, que se irá intensificando y dará lugar a los frecuentes y vigorosos movimientos de vida religiosa que reformarán el monacato en el siglo XIV.

A Cluny le sucederá la modalidad cisterciense que encarnan los monjes de San Bernardo, cuya característica más sobresaliente y moderna es la devoción a la humanidad de Cristo, a quien hay que amar "dulciter, prudenter, fortiter", para alcanzar la unión con Dios suave y amorosamente. La espiritualidad benedictina de los cistercienses descubrió modalidades nuevas para la piedad cristiana de los siglos XII y XIII, durante los cuales el monacato alcanzó las cotas más elevadas.

Pero ya en el siglo XIII se advierten los síntomas de una decadencia progresiva y generalizada. Una especie de languidez espiritual y molicie de vida socava los principios de la austeridad y ascetismo en los monasterios. Pese a las reformas emprendidas por Inocencio III y el concilio de Letrán IV, y posteriormente por Benedicto XIII, la disciplina monástica no se restablece, como lo demuestra èl abundante epistolario de Inocencio III o el concilio de Valladolid de 1322. Sin embargo, la ascesis cristiana prosigue en la paralela proliferación de los anacoretas. Estos, después de una temporada de vida solitaria o en pequeños grupos de habitabilidad eremítica, tienden a reagruparse en cenobios y piden el reconocimiento canónico de la Iglesia para continuar su vida de perfección evangélica en Religión jurídicamente constituida. Este fenómeno llegó a ser tan frecuente, que el concilio de Letrán IV trató de poner límite a tan gran variedad de religiones "para que no cause grave confusión en la Iglesia" ". Posteriormente, el año 1256, la bula Licet Ecclesiae canonizó la gran diversidad de grupos que existían y ios unificó a todos bajo le Regla de San Agustín, como la más idónea.

Estos movimientos de vida eremítica suponen el contrapeso al 'Jebilitamiento del monacato y oscurecimiento de los valores cris. tianos en el ocaso de la Edad Media. Aparecieron con mayor vitalidad en Italia durante la segunda mitad del siglo XIII y se extendieron con gran fuerza de atracción proselitista a lo largo de todo el:

8. Concilio de Letrán IV, canon 13, año 1215. 
siglo XIV. Figuras como Joaquín de Fiore (1130-1202) y San Francisco de Asis (1182-1228) y sus respectivos movimientos espirituaiistas, suscitaron una corriente de reforma y vivencia evangélica que condicionaría la vida religiosa del siglo XIV.

El fenómeno adquirió caracteres de popularidad. El penitente solitario, que se apartaba del mundo para entregarse a una vida de mortificación corporal puesta al servicio del espíritu, suscitaba admiración, gozaba de prestigio y se le aureolaba como a héroe de la cristiandad. En medio de este ambiente, surgió la figura del gran solitario del desierto de Calcis y después monje de Belén, y, en consecuencia, San Jerónimo se convirtió en el patrono y modelo de todos los solitarios y andariegos espirituales que se agrupaban en torno de maestros venerables: el beato Carlos de Montegranelli, Pedro Gambacorta de Pisa, Gualtero Marso, Juan Colombini y otros Inuchos. En casi todos ellos se da una especie de profetismo visionario de reforma entre soñada y presentida, al estilo de Joaquín de Fiore, el vislumbrador de la tercera edad de la Iglesia, la del Espíritu Santo, y una mística devoción por los "laudi" o himnos poéticos y devotos, propios de la espiritualidad franciscana, sencilla y evangélica, que pone al hombre en confraternidad con la naturaleza como criatura de Dios. Son los tiempos del beato Japone de Todi y Bianco de Siena, los cuales encarnan la apacible y atrayente figura de los monjes juglares italianos, que, por repetir insistentemente la exclamación "¡O Gesù, o Gesù!, recibieron el nombre popular de "gesuatos".

Pues bien, en este contorno de nueva espiritualidad entran en escena los eremitas del reino de Castilla y los ermitaños llegados de Italia siguiendo una inspiración visionaria y profética. Unos y otros se encontrarán en las soledades de las ermitas del Castañar (Toledo) y Villaescusa (Madrid), esperando la llegada del Espíritu Santo, que descendería sobre España para resucitar la Orden de San Jerónimo, según la profecía del maestro fray Thomas Succio de Siena (muerto en 1377), "de la tercera regla de San Francisco", a cuyo discipulado habían pertenecido los recién llegados de Italia, entre los cuales se encontraba fray Vasco, "natural de España, portugués de nación" 9. Por el mismo tiempo, Santa Brígida anunciaba al papa Gregorio XI, residente en Aviñón, "que en los reinos de Es-

9. JoSÉ DE SigügnzA, ob. cit., pág. 6. 
paña se había de resucitar y levantar como de nuevo la Orden de San Jerónimo" ${ }^{10}$.

Con este enfoque providencialista, característico de la historia del P. Sigüenza, fiel discípulo de San Agustín, comienza el historiador jerónimo la crónica de su Orden exponiendo "los principios y motivos del Cielo para la restauración de la Orden de San Jerónimo en los reinos de España" ${ }^{11}$.

\section{Fundación de la Orden jerónima}

Aquel grupo de ermitaños españoles e italianos, reunidos en las ermitas de nuestra Señora del Castañar y Villaescusa, terminaron por instalarse definitivamente en la de San Bartolomé de Lupiana. Al principio, su género de vida llamó la atención de las gentes favorablemente y despertó en muchos gran curiosidad; pero no pasó mucho tiempo sin que naciese la sospecha y comenzó a extenderse el rumor de que "era gente peligrosa, que tenía no sé qué manera de trato y lenguaje y aun orden de vida que sabía a los begardos y beguinos, que era como decir en estos tiempos luteranos", consigna el $\mathrm{P}$. Sigüenza ${ }^{12}$.

Esta sospecha de heterodoxia pronto les obligó a pensar en la conveniencia de solicitar la aprobación y confirmación papal como Órden religiosa canónicamente constituida. En efecto, el 15 de octubre de 1373, Gregorio XI les concedió en Aviñón la bula fundacional, Salvatoris Humani Generis, de la Orden de San Jerónimo bajo la Regla de San Agustín y las constituciones que tuvieran a bien elegir de las que regían entonces en el monasterio de Santa María del Santo Sepulcro, en Florencia ${ }^{13}$, hábito propio y facultad para fundar otros cuatro monasterios en los reinos de Castilla, León, Portugal, con el mismo título y organización que el de San Bartolomé de Lupiana, primer monasterio de los nuevos "frailes o ermitaños de San Jerónimo", los cuales tendrían como primer superior a Pedro Fernández Pecha o fray Pedro Fernández de Guadalajara ${ }^{14}$.

10. Ibidem., pág. 9.

11. Ibidem pág. 6 .

12. Ibidem pág. 21.

13. Balbino RaNo, "El monasterio de Santa María del Santo Sepulcro en Cámpora (Florencia) y la fundación de la Orden de San Jerónimo", en Stvdia Hieronymiana, I, págs. 75-102.

14. José DE SIGÜENZA, ob. cit., págs. 27-38. 
No obstante tener superior propio en cada monasterio, estaban sujetos a la jurisdición del Ordinario del lugar donde se encontraban. Con las primeras fundaciones, la Orden comenzó su expansión y sintieron la necesidad de tener autoridad propia que les mantuviera unidos con vínculos comunes. Esto motivó que solicitaran del papa la unión de todos los monasterios bajo una autoridad común y propia en la Orden con la consiguiente exención de las autoridades episcopales. El 18 de octubre de 1414, Benedicto XIII les concedió la unión tan deseada de todos los monasterios y la exención de los obispos. Esta gracia, concedida por el papa Luna, fue ratificada pocos años después, concluido el Cisma de Occidente, por Martín V, y posteriormente por Inocencio VIII en $1492{ }^{15}$.

De la vitalidad que por entonces tiene la Orden de San Jerónimo, nos da idea el hecho de que para el primer capítulo general, celebrado el año 1415 en el monasterio de Santa María de Guadalupe, acudan representantes de veinticinco monasterios de los más diversos lugares de la geografía hispana, de lo cual fray José de Sigüenza nos da cumplidos detalles ${ }^{16}$. También es el mismo historiador jerónimo quien nos declara el género de vida de los monjes y la finalidad inmediata que la Orden tenía establecida para alcanzar la santidad, cuando respecto de la problemática fusión de todas las religiones de jerónimos, pretendida por Nicolás $V$, por una parte nos dice que esta religión de San Jerónimo en España "tiene determinado desde sus principios ser pequeña, humilde, escondida y recogida; llevar a sus hijos por una senda estrecha, tratando dentro de sus paredes de la salud de sus almas, ocupándose continuamente de las alabanzas divinas, recompensa de las ofensas que por otra parte se hacen: orando, cantando, y llorando; servir a la Iglesia y aplacar la ira de Dios contra los pecados del mundo" ${ }^{17}$. $Y$ en otro lugar, más adelante, con palabras que pone en boca de fray Diego de Floristán, prior de la Mejorada (Valladolid), dirigidas al Pontífice tras madura reflexión de los jerónimos comisionados, nos declara la finalidad inmediata de la Orden jerónima española:

"El fin de esta Religión, Santísimo Padre, dijo fray Diego, es la contemplación y las alabanzas divinas; aquí endereza toda su manera de vida, sus leyes, constituciones, costumbres; para este fin tiene señaladas cada día ocho horas en el coro, sin otras

15. Ibidem págs. $277-180$.

16. Ibidem págs. 280-282.

17. Ibidem pág. 355 . 
deputadas para la oración mental y ejercicios particulares; para esto es menester grande recogimiento, no sólo dentro del convento, sino dentro de la celda; para esto se vive de ordinario en despoblados, donde en cuanto fuese posible no se sienta el trato del siglo; para esto tiene rentas y haciendas moderadas, quitando con ellas ocasión de mendigar, $\mathrm{y}$ de las salidas que tanto estorban $y$ distraen de este fin, embarazan el alma y turban el sosiego" ${ }^{18}$.

Este es el concepto que el historiador jerónimo tiene de la finalidad de su Orden, y lo que en este diálogo expositivo expone en boca de fray Diego, con tono preciso y humilde, lo explanará admirablemente a lo largo de toda su obra de escritor como maestro de espiritualidad ascética, dejando todo un tratado de teología monástica ${ }^{19}$, cuya vigencia se ha prolongado hasta nuestros tiempos.

La vida del monje jerónimo debe girar en torno a la contemplación y la liturgia, sin que nada le distraiga de esta divina ocupación, que enriquece el seno espiritual de la Iglesia y repara los pecados ajenos en la santidad de la vida monástica. En cuanto a la liturgia del altar y decoro de las ceremonias, la religión de San Jerónimo ha brillado siempre de tal manera, que las fundaciones reales sintieron particular predilección por ella en este sentido.

Conforme a este espíritu, un monje de nuestros días nos dice que hoy, como ayer, la Orden de San Jerónimo es "un instituto monástico que, en vida retirada, se dedica a las alabanzas divinas, a la contemplación y al trabajo. Los monjes comparten con los que vienen a ellos, mediante la hospitalidad y la limosna, el fruto de esa contemplación y trabajo. Los monasterios están organizados de forma que cada comunidad, en régimen de autonomía, reviste el carácter de una verdadera familia consagrada en nombre del Señor" ${ }^{20}$.

\section{Consolidación y extensión}

Durante los primeros cien años, la Orden fue consolidándose y conoció la expansión de sus monasterios por gran parte de la península. Numerosas fundaciones jerónimas hicieron acto de presencia en los puntos más remotos, aunque siempre, por lo general, en las cercanías de núcleos de población. Treinta y cinco monasterios sembraron de silencio y salmodias las provincias de Toledo,

18. Ibidem 357 .

19. JosÉ DE SIGÜENZA, Instrucción de Maestros, Escuela de Novicios, Arte de ìerfección religiosa y monástica, Madrid, 1712.

20. "Síntesis histórica de la Orden jerónima", en Stvdia Hieronymiana, I, pág. 28. 
Cáceres, Alicante, Valladolid, Valencia, Segovia, Sevilla, Guadalajara, etc. Atrajeron con su estilo de vida observante y recoleta, hospitalaria y laboriosa, la solemnidad de sus cultos y la fraternidad con el pueblo la atención de los monarcas y de los nobles.

Pero no todo fue siempre paz y armonía. Tres acontecimientos, de los que se hace eco su historiador seguntino, conmueven la Orden durante este primer siglo. Fray Lope de Olmedo pretendió introducir una regla nueva, sacada por él mismo de los escritos de San Jerónimo, para que sustituyera a la de San Agustín. Este intento respondía a una vieja tendencia en la vida monástica de introducir reformas en las religiones mediante nuevas congregaciones llamadas, generalmente, de "observancia". La Orden no aceptó la nueva Regla reformadora ni el cambio que suponía. Pero fray Lope, con la autorización del papa Martín $\mathrm{V}$, amigo y compañero de estudios, fundó la congregación de la observancia de San Jerónimo, que secundaba, por otra parte, los proyectos de reforma general dentro de la Iglesia, pretendidos por el pontífice después del Cisma de Occidente. No tuvo éxito la Congregación reformista y pronto los monasterios españoles de la rama lopista solicitaron la unión con los jerónimos primitivos. En cambio, en Italia pervivieron hasta el siglo $\mathrm{XX}$.

Nicolás $\mathrm{V}$, deseando la unificación y reforma de todos los monjes que ostentaban el patrocinio de San Jerónimo y llevaban su nombre en la Iglesia, pidió a los jerónimos españoles, en 1452, que acudieran a Roma, para celebrar allí capítulo general y tratar de la fusión de todos los jerónimos, de cuya federación los españoles ostentarian la primacia. Fray Diego de Floristán, como hemos visto, hizo desistir al pontífice de su proyecto demostrándole el dudoso resultado de esta pretensión ${ }^{21}$.

Por el prestigio alcanzado, la Orden jerónima se había hecho acreedora de la admiración y simpatía de los reyes y la nobleza, que la favorecieron con notables donaciones y privilegios. Las riquezas fueron acumulándose en los monasterios y atrajeron la atención de los ambiciosos. Primeramente los obispos formaron una liga para solicitar del papa que redujera a los jerónimos al tributo de los diezmos con efectos retroactivos de sesenta años, durante los cuales habían conseguido la exención por especiales privilegios. Diez

21. José de SIGÜEnZA, Historia..., I, págs. 354-358. 
años más tarde, en 1468, los nobles instaron al joven infante don Alfonso a que convirtiera la Orden en maestrazgo, para beneficiarse de sus cuantiosas rentas; pero la intervención del prior general, fray Alonso de Oropesa, impidió que se llevara a cabo. Un nuevo conato de desamortización, que fray José de Sigüenza califica de "el segundo y más riguroso trago que pasó en esta religión" ${ }^{22}$, tuvo lugar durante los primeros años del siglo XVI. Felipe I, fuertemente presionado por la nobleza y principalmente por su privado don Juan Manuel, estuvo a punto de firmar, en 1505, la disolución de la Orden de San Jerónimo, con el fin de desamortizarla de sus bienes; pero debido a causas, que el $P$. Sigüenza considera extraordinariamente providenciales, por no decir milagrosas, el intento tampoco llegó a ser realidad.

Durante la segunda centuria, quince nuevas fundaciones vitalizan aún más la Orden de los jerónimos. Entre todas ellas sobresale por su importancia la del monasterio de San Lorenzo el Real de El Escorial, cuya historia inmortalizó fray José ${ }^{23}$. En 1567 se agregaron los siete monasterios de la Congregación de fray Lope de OImedo, con lo cual la Orden quedaba unificada dentro del territorio nacional. En 1596 se suman los jerónimos de Portugal con sus nueve monasterios, originarios de la fundación de fray Vasco, como consecuencia de la unión política de ambas naciones, aunque volverían a independizarse con la separación de ambos reinos en 1675. Por todo ello, bien podemos decir que el siglo XVI, como en otros aspectos, es la época áurea de la Orden jerónima.

\section{De la decadencia a la restauración}

La decadencia comienza a producirse a finales del siglo XVII y se hace patente en el siglo XVIII. Coincide con la decadencia general del país y, aunque ,no faltaron voces que la advirtieron y se empeñaron en la renovación de la observancia monástica, la relajación interna avanzó progresivamente a medida que se enrarecía el ambiente político-social y religioso de la nación. La situación se agravó más aún con las invasiones napoleónicas y llegó a ser agó-

22. Ibidem II, pág. 87 .

23. Ibidem libros Tercero y Cuarto, págs. 401-682. Ha sido impresa cuatro veces. La úlitima, en la colección "Evocaciones y Memorias" de la editorial Aguilar: Fr. José DE SigüEnZA, Fundación del Monasterio de El Escorial. Prólogo de Federico-Carlos Sáinz de Robles. Con 33 ilustraciones. Madrid, 1963. 
nica con los decretos de exclaustración del período de 1808 a 1823. El golpe final lo recibiria la Orden con la exclaustración y desamortización de 1835.

La Orden de San Jerónimo, que por considerarse "española" desde sus orígenes no había fundado fuera de España, en cuanto a su rama masculina se refiere, al desaparecer del suelo patrio, dejó de existir por completo. Con ella quedaron conculcados importantes valores de orden histórico, cultural y religioso. Esta circunstancia es muy importante tenerla en cuenta para encontrar la explicación de que un escritor tan importante en las letras españolas como le consideran Menéndez Pelayo, Menéndez Pidal, Marañón, Pfandl, etc., permanezca desconocido largo tiempo y su obra olvidada entre los manuscritos de la Real Biblioteca de El Escorial, mientras que los demás clásicos resurgen con gran atractivo después del neoclasicismo. Es obra de los religiosos agustinos que han consagrado su vida al estudio en la biblioteca escurialense haber ido desvelando la figura de este gran estilista, cuyos escritos celosamente custodiaban, después que pregonó sus virtudes y méritos don Juan Catalina García en la Real Academia de la Historia en $1897^{24}$.

Aunque se hacen dos intentos de restauración, en 1854 en El Escorial y en 1884 en Guadalupe, éstos resultan ineficaces. La mayoría de sus miembros habian muerto y los que vivían se encontraban envejecidos y descorazonados para tan ardua empresa. Es a principios de nuestro siglo, en 1924, cuando se emprende la restauración que perdura hasta nuestros días. Se debió a las religiosas jerónimas ${ }^{25}$, que movieron a don Manuel Sanz a consagrar su vida a tan bello ideal. La empresa no resultaría fácil ni su realización inmediata. Don Manuel obtuvo de Pío XI la aprobación de su propósito y el 11 de agosto de 1925 acompañado de un grupo de jóvenes, se instaló en el entonces abandonado y ruinoso monasterio de $\mathrm{El}$

24. Juan Catalina García, Elogio de Fr. José de Sigülenza. Discurso de ingreso en la R.A.H., 20 de junio de 1897.

25. La rama femenina de jerónimas, tras próspera vida religiosa en España y América, y tras múltiples vicisitudes también en los últimos tiempos, mantiene el espíritu de su fundador, Fr. Pedro Fernández de Guadalajara, en la Federación Jerónima de Santa Paula, erigida por la Santa Sede el año 1957. Colaboraron decididamente en la restauración de los Jerónimos. en El Parral dos Padres Agustinos de la Provincia del Santísimo Nombre de Jesús de Filipinas: Fr. Jesús Delgado y Fr. José Pérez Gómez. 
Parral (Segovia), con el nombre religioso de fray Manuel de la Sagrada Familia. La restauración inciada se vio entorpecida por la República de 1931 y después por la Guerra de 1936, víctima de la cual fray Manuel murió en Paracuellos del Jarama. En El Parral permanecieron cinco monjes, a los cuales se unieron en 1941 un grupo de jóvenes que, pese a todas las dificultades, han mantenido la Orden de San Jerónimo hasta hoy.

Lorenzo Rubio González 